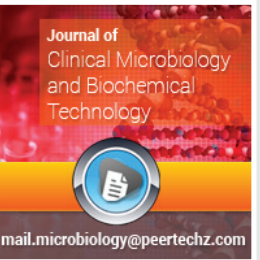

Clinical Group

\title{
Journal of Clinical Microbiology and Biochemical Technology
}

\section{Mohamed S. Attia Gaballah*, Mahmoud Youns, Zeinab A. Hassan}

Department of Biochemistry and Molecular Biology, Faculty of Pharmacy, Helwan University, Ain Helwan, Cairo, Egypt

Dates: Received: 03 July, 2017; Accepted: 05 August, 2017; Published: 07 August, 2017

*Corresponding author: Mohamed S. Attia Gaballah, Msc, Department of Biochemistry and Molecular Biology, Faculty of Pharmacy, Helwan University, Ain Helwan, Cairo, Egypt, E-mail: hamodi405@yahoo.com

Keywords: Talins; Talin1; Talin2; Integrins; Biomarker https://www.peertechz.com

\section{Review Article \\ Talins, hopes and promises}

\section{Talins Role in Different Types of Cells}

\section{Talins and platelet aggregation}

It has been shown that integrins are important for hemostasis and thrombosis because they trigger both platelet adhesion and aggregation. They are heterodimeric transmembrane receptors composed of an $\alpha$-and a $\beta$ - subunit that are expressed in a low affinity state in resting platelets. After activation, mediated by other platelet receptors, integrins shift to a high affinity state and efficiently bind their ligands [1].

The role of talin in mammalian integrin function in vivo was examined by selectively disrupting the talin1 gene in mouse platelet precursor megakaryocytes. Talin null megakaryocytes produced circulating platelets that displayed normal morphology while manifested profoundly impaired hemostatic function. Specifically, platelet-specific deletion of talin1 led to spontaneous hemorrhage and pathological bleeding. These experiments demonstrated that talin is required for inside-out activation of platelet integrins in hemostasis and thrombosis $[2,3]$.

\section{Talins and B-lymphocytes homing in lymph nodes}

CD19 cre-mediated depletion of talin1 in B cells shows that talin1 was not required for B-cell generation in the bone marrow or for the entry of immature B cells to the white pulp of the spleen. Furthermore, loss of talin1 also did not affect B-cell maturation into follicular B cells but compromised differentiation of marginal zone B cells. Nevertheless, serum IgM and IgG levels remained normal.
However, ex-vivo analysis of talin1-deficient spleen B cells indicated an important role for talin1 in lymphocyte functionassociated antigen-1 (LFA-1) and very late antigen-4 (VLA-4) activation stimulated by canonical agonists, but not in B-cell chemotaxis. As a result, talin1 null B splenocytes could not enter lymph nodes nor return to the bone marrow. Talin1 deficiency in B cells was also impaired in the humoral response to a T cell-dependent antigen.

Collectively, these results indicate that talin1 is not required for follicular B-cell maturation in the spleen or homeostatic humoral immunity but is critical for integrin-dependent B lymphocyte emigration to lymph nodes and optimal immunity against $\mathrm{T}$-dependent antigens [4].

\section{Talins and $\mathrm{T}$ cell activation and $\mathrm{T}$ cell stopping}

It has been revealed that $\mathrm{T}$ cell- antigen presenting cell (APC) contact initiates T cell activation and is maintained by the integrin lymphocyte function- associated antigen-1 (LFA-1). Talin1-deficient $\mathrm{T}$ cells showed defects in contact-dependent $\mathrm{T}$ cell stopping and proliferation. While, did not form stable interactions with APCs, transient contacts were sufficient to induce signaling.

In contrast to prior models, LFA-1 was polarized to $\mathrm{T}$ cell:APC contacts in talin1-deficient $\mathrm{T}$ cells but vinculin and F-actin polarization at the immune synapse was impaired. These results Indicate that $\mathrm{T}$ cell proliferation requires sustained, talin1-mediated T cell:APC interactions and that talin1 is necessary for F-actin polarization and the stability of immune synapses [5]. 


\section{Talins and NK cells cytotoxicity}

LFA-1 is critical for natural killer (NK) cell cytotoxicity because it mediates adhesion of NK cells to target cells. Talin is also required for LFA-1-mediated outside-in signaling leading to NK cell polarization. NK cells generated from talin1deficient murine embryonic stem cells are defective in LFA1-mediated adhesion. Although exogenously added manganese could activate LFA-1 on talin-deficient NK cells and induce conjugate formation with target cells, their LFA-1-dependent cytotoxicity is impaired.

Furthermore, binding of ICAM- 1-coated beads to wildtype NK cells induces reorganization of the actin cytoskeleton and coligation of the activating receptor NKG2D induces polarization of cytotoxic granules, whereas talin1-deficient NK cells fail to polarize with or without NKG2D coligation. So, talin1 plays a dual role in NK cell cytotoxicity, first by activation of LFA-1-mediated adhesion and then via LFA-1-induced NK cell polarization [6].

\section{Talins and skeletal muscle}

It was found that Talin 1 and 2 are required for myoblast fusion, sarcomere assembly and the maintenance of myotendinous junctions. Talin 1 and 2 connect integrins to the actin cytoskeleton and regulate the affinity of integrins for ligands. In skeletal muscle, talin 1 regulates the stability of myotendinous junctions (MTJs). Concomitant deletion of talin 1 and 2 leads to defects in myoblast fusion and sarcomere assembly, resembling defects in muscle lacking $\beta 1$ integrins.

Talin 1/2-deficient myoblasts express functionally active $\beta 1$ integrins, suggesting that defects in muscle development are not primarily caused by defects in ligand binding, but rather by disruptions of the interaction of integrins with the cytoskeleton. Consistent with this finding, assembly of integrin adhesion complexes is perturbed in the remaining muscle fibers of talin 1/2-deficient mice. Consequently, talin 1 and 2 are crucial for skeletal muscle development, where they regulate myoblast fusion, sarcomere assembly and the maintenance of MTJs [7].

\section{Talins and Osteoclast function}

TLN1(fl/fl) mice with those expressing cathepsin K-Cre (CtsK-TLN1) were mated to delete the gene in mature osteoclasts, or with lysozyme M-Cre (LysM-TLN1) mice to delete TLN1 in all osteoclast lineage cells in order to determine talin1's role in osteoclasts,. TLN1 absence impairs macrophage colony-stimulating factor (M-CSF) stimulated inside-out integrin activation and cytoskeleton organization in mature osteoclasts.

Moreover,Talin1-deficient precursors normally express osteoclast differentiation markers when exposed to M-CSF and receptor activator of nuclear factor $\kappa \mathrm{B}$ (RANK) ligand, but attach to substrate and migrate poorly, stopping their development into mature resorptive cells. In keeping with inhibited resorption, CtsK-TLN1 mice exhibit an $\sim 5$ fold increase in bone mass. Osteoclast-specific deletion of Rap1
(CtsK-Rap1), which promotes talin/ $\beta$ integrin recognition, yields similar osteopetrotic mice.

The fact that the osteopetrosis of CtsK-TLN1 and CtsK-Rap1 mice is substantially more severe than that of those missing $\alpha \mathrm{v} \beta 3$ is likely due to added failed activation of $\beta 1$ integrins. In keeping with osteoclast dysfunction, mice in whom talin is deleted late in the course of osteoclastogenesis are substantially protected from ovariectomy-induced osteoporosis and the periarticular osteolysis attending inflammatory arthritis. Thus, talin1 and Rap1 are critical for resorptive function and their selective inhibition, in mature osteoclasts, retards pathological bone loss [8].

\section{Talin and maintenance of the regulatory $T$ cell pool}

Recent study has described a role for talin in maintaining the homeostasis and survival of the regulatory $\mathrm{T}$ (Treg) cell pool. T cell-specific deletion of talin in Tln1fl/flCd4Cre mice resulted in spontaneous lymphocyte activation, primarily due to numerical and functional deficiencies of Treg cells in the periphery. Peripheral talin-deficient Treg cells were unable to maintain high expression of $\mathrm{IL}-2 \mathrm{R} \alpha$, resulting in impaired IL-2 signaling and ultimately leading to increased apoptosis via downregulation of prosurvival proteins $\mathrm{Bcl}-2$ and $\mathrm{Mcl}-$ 1. The requirement for talin in maintaining high $\mathrm{IL}-2 \mathrm{Ro}$ expression by Treg cells was due, in part, to integrin LFA-1mediated interactions between Treg cells and dendritic cells This data suggests a critical role for talin in Treg cell-mediated maintenance of immune homeostasis [9].

\section{Talins Role in Some Diseases}

\section{Talin is a mechanosensitive molecule in health and di- sease}

It has recently proved that Talin is one of a handful molecules that can expose new recognition sites when undergoing force-induced mechanical unfolding, and it can bind and recruit cytoskeletal proteins that are involved in mechanotransduction. Talin has attracted great importance in the field of mechanobiology due to its plasticity in undergoing conformational changes under force stimulation beside its cellular localization that bridges the cytoskeleton with the extra cellular matrix. In addition to these roles in healthy cells, the dysregulation of talin activators can lead to disease states in which aberrant integrin activation and mechanotransduction precipitate changes in cell spreading, migration, and survival. Novel data have implicated a role for talin in diseases that are highly regulated by mechanical cues. In this review, we present the current understanding of talin structure, its relationship to binding partners, and its role in disease states [10].

\section{Talins and psoriasis}

The integrated proteomic and peptidomic analysis identified a number of proteins and their fragments present at different concentrations in the plasma of psoriasis patients and healthy donors. Enzyme linked immunosorbent assay (ELISA) was used independently to verify the changes in the concentrations of several of these proteins. 
Increased concentrations of cytoskeletal and actin-binding proteins and their peptides in psoriatic plasma, suggested disease-related cell leakage of these proteins and their increased proteolysis. Among the increased plasma proteins and peptides were thymosin $\beta 4$, talin 1 , actin $\gamma$, filamin, and profilin.

Furthermore, increased concentrations of $\mathrm{Ca}^{+}$-binding proteins calgranulins $\mathrm{A}$ and $\mathrm{B}$ in psoriatic plasma were also observed, confirming previous reports, and appeared to be relevant to the increase of cytoskeletal components. Decreased fibrinogen fragments were another notable change in psoriatic plasma [11].

\section{Talins and rheumatoid arthritis}

It has been reported that, plasma talin is a clinically useful new biomarker for diagnosis and monitoring for rheumatoid arthritis using the commercially available enzyme linked immunosorbent assay (ELISA) kits [12].

\section{Talins and Multiple Sclerosis}

Previously, it has been identified anti-Talin-1 antibodies in the serum of MS. Recently, they measured the serum soluble Talin-1 (sTalin-1) levels by enzyme-linked immunosorbent assay. The serum sTalin-1 levels were significantly higher in patients with MS than in normal controls and in the acute phase of disease than in the remission phase. Interestingly, serum sTalin-1 levels were associated with a sustained increase in disability after MS attack but not with serum anti-Talin-1 antibody levels. sTalin-1 may be a biomarker for the acute phase of MS and may be used for the short-term prognosis of MS [13].

\section{Conclusion}

For a critical care clinician, Talin analysis could be particularly helpful as a diagnostic or prognostic tool in many types of diseases. The presence of elevated levels of talin in various critically ill clinical states and its correlation with disease severity augments its role as a prognostic biomarker in clinical practice and as a good target for treatment of diseases. However, further studies using this biomarker in various clinical settings will ultimately prove their cost-effectiveness and clinical usefulness.

\section{References}

1. Shattil SJ, Kashiwagi H, Pampori N (1998) Integrin signaling: the platelet paradigm. Blood 91: 2645-2657. Link: https://goo.gl/SSb2N2

2. Nieswandt B, Moser M, Pleines I, Varga-Szabo D, Monkley S, et al. (2007) Loss of talin 1 in platelets abrogates integrin activation, platelet aggregation, and thrombus formation in vitro and in vivo. J Exp Med 204: 3113-3118. Link: https://goo.gl/oRKxAu

3. Petrich BG, Marchese P, Ruggeri Z, Spiess S, Weichert R, et al. (2007) Talin is required for integrin-mediated platelet function in hemostasis and thrombosis. J Exp Med 204: 3103-3111. Link: https://goo.gl/tsxHPG

4. Manevich-Mendelson E, Grabovsky V, Feigelson S, Cinamon G, Gore Y, et al. (2010) Talin1 is required for integrin-dependent $B$ lymphocyte homing to lymph nodes and the bone marrow but not for follicular B-cell maturation in the spleen. Blood 116: 5907-5918. Link: https://goo.gl/bZFiJq

5. Wernimont SA, Wiemer AJ, Bennin DA, Monkley SJ, Ludwig T, et al. (2011) Contact-dependent $\mathrm{T}$ cell activation and $\mathrm{T}$ cell stopping require talin1. J Immunol 187: 6256-6267. Link: https://goo.gl/nwjfWT

6. Mace EM, Monkley SJ, Critchley DR, Takei F (2009) A Dual Role for Talin in NK Cell Cytotoxicity: Activation of LFA-1-Mediated Cell Adhesion and Polarization of NK Cells. J Immunol 182: 948-956. Link: https://goo.gl/YJFjfi

7. Conti FJ1, Monkley SJ, Wood MR, Critchley DR, Müller U (2009) Talin 1 and 2 are required for myoblast fusion, sarcomere assembly and the maintenance of myotendinous junctions. Development 136: 3597-606. Link: https://goo.gl/9r2NAo

8. Zou W, Izawa T, Zhu T, Chappel J, Otero K, et al. (2013) Talin1 and Rap1 are critical for osteoclast function. Mol Cell Biol 33: 830-844. Link: https://goo.gl/fFypQz

9. Klann J, Remedios K, Kim S, Metz P, Lopez J, et al. (2017) Talin plays a critical role in the maintenance of the regulatory $T$ cell pool. J Immunol 198: 46394651. Link: https://goo.gl/6Jx2PK

10. Haining AW, Lieberthal TJ, Del Río Hernández A (2016) Talin: a mechanosensitive molecule in health and disease. FASEB J 6: 2073-2085. Link: https://goo.gl/1cjDuT

11. Plavina T, Hincapie M, Wakshull E, Subramanyam M, Hancock WS (2008) Increased Plasma Concentrations of Cytoskeletal and Ca2+ Binding Proteins and Their Peptides in Psoriasis Patients. Clin Chem 54: 1805-1814. Link: https://goo.gl/MW95wU

12. Tsuzaka K, Itami Y, Shinozaki N, Tetsuo M (2011) Plasma Talin Is a New Diagnostic and Monitoring Marker for Rheumatoid Arthritis. [Abstract] Arthritis Rheum 63: 357. Link: https://goo.gl/KoUs2f

13. Muto M, Mori M, Liu J, Uzawa A, Uchida T, et al. (2017) Serum soluble Talin-1 levels are elevated in patients with multiple sclerosis, reflecting its disease activity. J Neuroimmunol 305: 131-134. Link: https://goo.gl/XpUhwF 